\title{
The Stanley Foundation Bipolar Network: Results of the Naturalistic Follow-Up Study after 2.5 Years of Follow-Up in the German Centres ${ }^{1}$
}

\author{
S. Dittmanna N.C. Biedermann ${ }^{b} \quad$ H. Grunzea $\quad$ B. Hummela L.O. Schärer ${ }^{b}$ \\ N. Kleindienst ${ }^{a}$ A. Forsthoffa N. Matzner ${ }^{a} \quad$ S. Walser ${ }^{b} \quad J$. Walden $^{b}$ \\ Departments of Psychiatry, a University of Munich, Munich, and bUniversity of Freiburg, Freiburg, Germany
}

\section{Key Words}

Bipolar disorder · Course of illness · Comorbidity · Mood stabilizer · Treatment · Stanley Foundation

\begin{abstract}
The Stanley Foundation Bipolar Network (SFBN) is an international, multisite network investigating the characteristics and course of bipolar disorder. Methods (history, ratings and longitudinal follow-up) are standardized and equally applied in all 7 centres. This article describes demographics and illness characteristics of the first 152 German patients enrolled in the SFBN as well as the results of 2.5 years of follow-up. Patients in Germany were usually enrolled after hospitalisation. More than $72 \%$ of the study population suffered from bipolar I disorder and $25 \%$ from bipolar II disorder. The mean \pm SD age of the study participants was $42.08 \pm 13.5$ years, and the mean \pm SD age of onset $24.44 \pm 10.9$ years. More than $40 \%$ of the sample reported a rapid-cycling course in history, and even more a cycle acceleration over time. $37 \%$ attempted suicide at least once. $36 \%$ had an addi-
\end{abstract}

1 This study was supported by the Stanley Medical Research Institute. tional Axis I disorder, with alcohol abuse being the most common one, followed by anxiety disorders. During the follow-up period, only $27 \%$ remained stable, $56 \%$ had a recurrence, $12.8 \%$ perceived subsyndromal symptoms despite treatment and regular visits. $27 \%$ suffered from a rapid-cycling course during the follow-up period. Recurrences were significantly associated with bipolar I disorder, an additional comorbid Axis I disorder, rapid cycling in history, a higher number of mood stabilizers and the long-term use of typical antipsychotics. Rapid cycling during follow-up was only associated with a rapidcycling course in history, a higher number of mood stabilizers and at least one suicide attempt in history.

Copyright $\odot 2003$ S. Karger AG, Basel

\section{Introduction}

Bipolar disorder is a common, severe and persistent illness with a prevalence rate of $1.3-1.7 \%[1,2]$. According to some authors who also include bipolar spectrum disorders, the prevalence rate increases to 3-7\% [3-6]. Taking this into account, bipolar illness affects at least 1 million people in Germany, about 4 million in the USA and 3.2 million people in Europe. Even though research

\begin{tabular}{ll}
\hline KARGER & ( ) 2002 S. Karger AG, Basel \\
0302-282X/02/0465-0002\$18.50/0 \\
$\begin{array}{l}\text { Fax +4161306 1234 } \\
\begin{array}{l}\text { E-Mail karger@karger.ch } \\
\text { www.karger.com }\end{array}\end{array}$ & $\begin{array}{l}\text { Accessible online at: } \\
\text { www.karger.com/nps }\end{array}$
\end{tabular}

Sandra Dittmann
Psychiatrische Klinik der LMU, Nussbaumstrasse 7
D-80336 München (Germany)
Tel. +49 8951605781 , Fax +49 8951605330
E-Mail sandra.dittmann@psy.med.uni-muenchen.de 
efforts have been reinforced lately, many questions still remain open concerning the course, treatment and origins of this devastating illness. In 1989 and 1994, the National Institute of Mental Health organized two bipolar disorder workshops which concluded that there is still an enormous need for research on bipolar illness [7, 8]. Especially the need for controlled clinical treatment trials for bipolar depression and maintenance treatment was emphasized. Furthermore, the two workshops recommended the development of a consortium of academic centres, patient advocacy groups and the pharmaceutical industry to increase the number and representativeness of patients in controlled clinical trials and to help develop methods and assessment devices that would accurately describe the illness course [9]. As a result, the Stanley Foundation Bipolar Network (SFBN) was established with the generous support of Vada and Theodore Stanley in order to improve research for bipolar affective disorders. A detailed description of the SFBN, its rationale and the methods used is published elsewhere [10-12]. In brief, the aim of the Network is to enroll a large number of bipolar patients for longitudinal studies. Patients are seen at least once a month and psychopathology is assessed using well-known, validated rating scales and prospective life chart methodology [13]. Depending on the course of the illness, patients are offered to participate in randomized open or doubleblind clinical trials. Patients not eligible or willing to participate in clinical treatment trials are followed up in the Naturalistic Follow-up Study (NFS). Treatment of these patients is not restricted, but up to the clinician's choice. The results of the NFS of the two German centres after 2.5 years of follow-up are presented in this paper.

\section{Methodology}

Until 1998, the Network had been composed of four University Hospitals in the USA (Bethesda, Los Angeles, Dallas and Cincinnati) and one in The Netherlands (Utrecht). In 1999, the Psychiatric Hospitals of the Universities of Munich and Freiburg, Germany joined the SFBN as affiliated sites. In Germany, patients recruited to the study were usually enrolled after hospitalisation or by self-referral. All patients provided written informed consent prior to entering the network. The inclusion criteria for entry were the diagnosis of bipolar disorder (I, II, NOS) or schizoaffective disorder (bipolar type) according to DSM-IV, age older than 18 years and the willingness to return for monthly follow-up visits. Comorbid psychiatric or medical illnesses were no exclusion criteria, except any substance abuse requiring acute treatment.

At entry, the diagnosis and other Axis I disorders were confirmed using the Structured Clinical Interview of DSM-IV [14]. Demographic and clinical variables were assessed using questionnaires completed by clinicians and patients [9]. Axis II disorders (Personality
Disorder Questionnaire [15]), depressive [Inventory of Depressive Symptoms [16] (IDS)], manic [Young Mania Rating Scale [17] (YMRS)] and psychotic symptomatology [Positive and Negative Syndrome Scale [18] (PANSS)], overall mood [Clinical Global Impressions Scale for Bipolar Illness [19] (CGI-BP)] and global functioning [Global Assessment of Functioning Scale [20] (GAF)] were assessed as well. The course of the illness was assessed using the retrospective and prospective Life-Chart Methodology (LCM) [13].

Patients were usually followed up monthly, but when clinically indicated, also more often. At every follow-up visit, the same psychometric scales were applied again (IDS, YMRS, CGI-BP, GAF, LCM) to assess symptomatology, the course of illness and treatment.

Patients had the choice to receive their medical care entirely at the Stanley Research Clinics or to visit a psychiatrist in a private practice. Treatment in the NFS was not standardized, but was up to the treating psychiatrist's choice depending on the course of the illness.

Statistical analyses were performed using the Statistical Products for Service Solutions version 10.1. Frequencies were run on demographic and clinical variables as well as treatment characteristics. Fisher's exact test was used to test significance for categorical, Student's t test was used to evaluate continuous variables. Statistical significance was set at 0.05 (two-tailed).

\section{Results}

More than 700 patients with bipolar or schizoaffective disorders have been enrolled in the whole Network so far [9]. In Germany, 152 patients have been enrolled consecutively since 1999 and have been followed up prospectively for an average of 13.13 months (1-32 months).

\section{Clinical and Demographic Variables of the Sample}

Table 1 shows the most important demographic and clinical variables of the 152 patients enrolled in Germany. Most patients suffer from a bipolar I disorder (72.1\%), followed by patients with bipolar II disorder (25.2\%). Only few patients with a bipolar disorder NOS or schizoaffective disorder participated in the study $(0.7$ and $2 \%$, respectively). The distribution of age and sex is comparable with other cohort studies of bipolar patients $[9,21]$. Almost $60 \%$ of the patients lived on their own, either in an apartment or in sheltered housing. Only $40 \%$ lived together with their partners or families. This is also in line with other studies [22]. While in many epidemiologic studies most bipolar patients also suffer from comorbid Axis I disorders, above all substance abuse and anxiety disorders, in our sample, only $35.8 \%$ of the patients had had an additional Axis I disorder during their lifetime, of which substance abuse was the most common one (26.3\%), followed by anxiety disorders (12.5\%). Only few patients also suffered from an eating disorder (7.2\%). 
Table 1. Demographic and clinical variables

\begin{tabular}{|c|c|c|c|}
\hline & $\begin{array}{l}\text { Whole sample } \\
(\mathrm{n}=152)\end{array}$ & $\begin{array}{l}\text { Bipolar I } \\
(\mathrm{n}=108)\end{array}$ & $\begin{array}{l}\text { Bipolar II } \\
(\mathrm{n}=38)\end{array}$ \\
\hline Current age, years & $42.08 \pm 13.5(21-80)$ & $40.95 \pm 12.62$ & $45.89 \pm 15.10$ \\
\hline \multicolumn{4}{|l|}{ Gender, $\%$} \\
\hline Female & 51.7 & 50.9 & 50.0 \\
\hline Male & 48.3 & 49.1 & 50.0 \\
\hline \multicolumn{4}{|l|}{ Marital status, $\%$} \\
\hline Married/cohabitation & 40.4 & 37.4 & 44.7 \\
\hline Widowed & 2.1 & 1.9 & 7.9 \\
\hline Divorced/separated & 15.7 & 14.1 & 21.1 \\
\hline Single & 41.8 & 46.2 & 26.3 \\
\hline \multicolumn{4}{|l|}{ Current living situation, $\%$} \\
\hline With spouse/partner & 40.4 & 36.8 & 47.4 \\
\hline Single parent & 2.1 & 0.9 & 5.3 \\
\hline Single & 46.4 & 49.1 & 44.7 \\
\hline With family of origin & 8.2 & 9.4 & 2.6 \\
\hline In group home & 1.4 & 1.9 & 0 \\
\hline Other & 1.4 & 1.9 & 0 \\
\hline \multicolumn{4}{|l|}{ Diagnosis, $\%$} \\
\hline Bipolar I & 72.1 & & \\
\hline Bipolar II & 25.2 & & \\
\hline Bipolar NOS & 0.7 & & \\
\hline Schizoaffective disorder & 2.0 & & \\
\hline Age of onset, years & $24.44 \pm 10.9(9-63)$ & $23.97 \pm 11.2(13-63)$ & $25.82 \pm 10.5(9-50)$ \\
\hline Age at first treatment & $29.77 \pm 10.6$ & $29.65 \pm 11.5$ & $29.94 \pm 9.3$ \\
\hline Age at first hospitalisation & $31.11 \pm 13.2$ & $30.45 \pm 12.2$ & $31.57 \pm 13.7$ \\
\hline Comorbid Axis I disorders, $\%$ & 35.8 & 35.9 & 37.8 \\
\hline Any substance abuse & 26.3 & 25.5 & 28.9 \\
\hline Alcohol abuse & 17.8 & 18.9 & 18.4 \\
\hline Substance abuse (without alcohol) & 8.5 & 6.6 & 10.5 \\
\hline Any anxiety disorder & 12.5 & 10.4 & 18.4 \\
\hline Any eating disorder & 7.2 & 9.4 & 0 \\
\hline
\end{tabular}

Table 2 shows the distribution of the socioeconomic status of the sample. Even though many patients were highly educated (28.3\% finished university or a comparable education), only one third of the sample was able to work full-time in jobs which matched their qualifications. Most of the patients were unable to work (13.5\%), retired (26.6\%) unemployed $(7.8 \%)$ or in rehabilitation programs (3.5\%). The limitation of the occupational functioning is also obvious from household income. One third of the bipolar patients has to live with less than 10,000 EUR/ year, more than half of the sample with less than 20,000 EUR/year.

When asked for their own judgement, more than two thirds $(61.4 \%)$ of the patients feel that their occupational functioning is limited moderately to severely due to their bipolar illness even in free intervals.

Important illness characteristics are shown in table 3. Almost $41 \%$ of the patients reported a history of rapid cycling. No significant differences were found between the diagnostic groups (data not shown). Almost 14\% of the sample suffered from ultradian cycling which was defined as cycling within a day. Almost half of the sample (44.7\%) reported a worsening of their illness over time due to cycle acceleration, a substantial number of patients additionally reported an increase in severity. These findings are also in line with other studies [9, 22]. There is a big difference between the number of episodes and hospitalizations. While the vast majority of patients $(83.4 \%)$ 
Table 2. Socioeconomic status

\begin{tabular}{|c|c|c|c|}
\hline & $\begin{array}{l}\text { Whole sample } \\
(\mathrm{n}=152)\end{array}$ & $\begin{array}{l}\text { Bipolar I } \\
(\mathrm{n}=108)\end{array}$ & $\begin{array}{l}\text { Bipolar II } \\
(\mathrm{n}=38)\end{array}$ \\
\hline \multicolumn{4}{|l|}{ Employment status, \% } \\
\hline \multicolumn{4}{|l|}{ Full-time } \\
\hline Equal to qualifications & 29.6 & 26.4 & 34.2 \\
\hline In household & 2.8 & 2.9 & 5.3 \\
\hline Below qualifications & 2.8 & 2.9 & 2.6 \\
\hline Part-time & 7.8 & 5.9 & 10.5 \\
\hline Unemployed & 7.8 & 5.9 & 13.2 \\
\hline Rehabilitation program/sheltered workshop & 3.5 & 4.9 & 0.0 \\
\hline Unable to work & 13.5 & 17.6 & 2.6 \\
\hline Retired/disability pension & 26.6 & 27.5 & 23.7 \\
\hline Other & 6.4 & 5.9 & 7.9 \\
\hline \multicolumn{4}{|l|}{ Education, $\%$} \\
\hline Hauptschulabschluss (10 years) & 8.1 & 5.7 & 10.5 \\
\hline Mittlere Reife (High school) & 8.7 & 10.4 & 5.3 \\
\hline Abitur (13 years) & 26.2 & 31.1 & 13.2 \\
\hline Apprenticeship & 28.9 & 26.4 & 36.8 \\
\hline University & 22.9 & 12.6 & 23.7 \\
\hline Graduation & 5.4 & 3.8 & 10.5 \\
\hline \multicolumn{4}{|l|}{ Household income in DM, \% } \\
\hline$<20,000$ & 30.6 & 32.4 & 24.3 \\
\hline $20,000-39,999$ & 25.9 & 29.5 & 16.2 \\
\hline $40,000-59,999$ & 13.6 & 14.3 & 10.8 \\
\hline $60,000-79,999$ & 12.9 & 9.5 & 21.6 \\
\hline $80,000-99,999$ & 6.1 & 4.8 & 10.8 \\
\hline $100,000+$ & 9.5 & 7.6 & 16.2 \\
\hline \multicolumn{4}{|c|}{ Occupational functioning limited by bipolar illness (free interval), $\%$} \\
\hline Not limited & 0.8 & 1.1 & 0 \\
\hline Mildly & 37.8 & 36.6 & 38.9 \\
\hline Moderately & 23.6 & 24.7 & 25.0 \\
\hline Markedly & 15.0 & 17.2 & 11.1 \\
\hline Severely & 12.6 & 10.8 & 11.1 \\
\hline No free interval & 10.2 & 9.7 & 13.9 \\
\hline
\end{tabular}

have suffered from at least 5 episodes in their lives, only half of the patients have been hospitalized as often as that. The difference is even clearer in patients which have suffered from more than 20 episodes. While almost $40 \%$ of the sample say they have had at least 20 episodes in their lifetime, only $9.2 \%$ have also been hospitalized as often as that. There was no statistical difference between the two major diagnostic groups (data not shown).

\section{Results of the Follow-Up Period}

During the prospective observation period, only $27 \%$ of all patients remained free of symptoms. The majority of patients $(56 \%)$ suffered from at least one recurrence. $12.8 \%$ of the patients perceived subsyndromal symptoms not long or severe enough to fulfil the diagnostic criteria for a recurrence. That means a vast majority of the sample $(68.8 \%)$ suffered from mood disturbances despite treatment adherence and regular visits to a professional. About a quarter of the study population suffered from a rapidcycling course during follow-up (26.5\%). The treatment of 111 patients of the sample could be analysed more precisely. Of this subsample, almost all $(97.3 \%)$ were on at least 1 mood stabilizer during follow-up. Most of the patients were on just 1 mood stabilizer (60.4\%), about one third of the sample (33.3\%) had a combination treatment of 2 mood stabilizers, and the remaining patients were on either 3 or 4 mood stabilizers (2.7 and $0.9 \%$, respectively). Even though there is a wide range of treatment options now, the most important mood stabilizer is still lithium. Almost one quarter of our sample $(23.1 \%)$ were on lithi- 
Table 3. Illness characteristics

\begin{tabular}{|c|c|c|c|}
\hline & $\begin{array}{l}\text { Whole sample } \\
(\mathrm{n}=141)\end{array}$ & $\begin{array}{l}\text { Bipolar I } \\
(\mathrm{n}=107)\end{array}$ & $\begin{array}{l}\text { Bipolar II } \\
(\mathrm{n}=36)\end{array}$ \\
\hline History of rapid cycling, $\%$ & 40.7 & 39.8 & 41.2 \\
\hline No rapid cycling & 59.3 & 60.2 & 58.8 \\
\hline Rapid cycling & 16.8 & 14.0 & 20.6 \\
\hline Ultra-rapid cycling & 9.9 & 11.8 & 5.9 \\
\hline Ultradian cycling & 13.7 & 14.0 & 14.7 \\
\hline \multicolumn{4}{|l|}{ Number of episodes, $\%$} \\
\hline $1-4$ & 16.5 & 14.6 & 20.6 \\
\hline $5-10$ & 26.3 & 24.0 & 32.4 \\
\hline $11-20$ & 17.3 & 19.8 & 11.8 \\
\hline $20+$ & 39.8 & 41.7 & 35.3 \\
\hline \multicolumn{4}{|l|}{ Hospitalizations, $\%$} \\
\hline $0-4$ & 54.6 & 53.5 & 54.8 \\
\hline $5-10$ & 26.1 & 25.6 & 29.0 \\
\hline $11-20$ & 10.1 & 9.3 & 12.9 \\
\hline $20+$ & 9.2 & 11.6 & 3.2 \\
\hline Cycle acceleration, $\%$ & 44.7 & 44.4 & 38.9 \\
\hline More severe episodes of depression & 55.1 & 51.0 & 66.7 \\
\hline More severe episodes of hypomania & 34.4 & 35.7 & 35.3 \\
\hline More severe episodes of mania & 38.6 & 41.2 & 0 \\
\hline \multicolumn{4}{|l|}{ History of suicide attempts, $\%$} \\
\hline None & 63.4 & 62.8 & 63.9 \\
\hline At least 1 & 36.6 & 37.2 & 36.1 \\
\hline More than 4 & 7.5 & 8.5 & 5.6 \\
\hline \multicolumn{4}{|l|}{ Interepisode symptoms, $\%$} \\
\hline No symptoms & 42.0 & 42.4 & 42.9 \\
\hline Mild symptoms & 38.9 & 37.0 & 42.9 \\
\hline Significant symptoms & 4.6 & 4.3 & 2.9 \\
\hline Substantial symptoms & 2.3 & 3.3 & 0 \\
\hline Cycle continuously & 12.2 & 13.0 & 11.4 \\
\hline \multicolumn{4}{|l|}{ Feeling of stigmatization, $\%$} \\
\hline Not at all & 31.7 & 29.2 & 37.1 \\
\hline Mild & 26.8 & 27.0 & 25.7 \\
\hline Moderate & 30.1 & 33.7 & 25.7 \\
\hline Severe & 11.4 & 10.1 & 11.4 \\
\hline
\end{tabular}

um alone, another $21.2 \%$ on a combination treatment of lithium and another mood stabilizer (e.g. valproate or carbamazepine). An increasing number of patients is also on a combination treatment of lithium and an atypical antipsychotic $(4.6 \%)$. Valproate alone or in combination with another mood stabilizer was the treatment of choice in $30.3 \%$ of the study population. Interestingly, there is still a high proportion of patients who also get a long-term treatment with antidepressants or typical antipsychotics (for at least 6 months, 42.3 and 24.5\%, respectively). During the observation period, 50 patients (33\%) dropped out for various reasons.

\section{Recurrences}

About $56 \%$ of the patients suffered from at least one recurrence in the follow-up period. Patients with a bipolar I disorder significantly more often had a recurrence than patients with a bipolar II disorder $(p<0.044)$. Furthermore, patients with an additional comorbid Axis I disorder or a rapid-cycling course in history also suffered more often from a recurrence than patients without any $(\mathrm{p}<$ 0.047 and $p<0.005$, respectively). However, there is also another significant difference: patients who had a recurrence during the follow-up period were on significantly more mood stabilizers and more often on an additional 
Table 4. Recurrence during follow-up

\begin{tabular}{llll}
\hline & Recurrence & No recurrence & p value \\
\hline Age $^{1}$ & $43.18 \pm 13.50$ & $39.32 \pm 11.43$ & 0.081 \\
Age of onset $^{1}$ & $24.12 \pm 11.66$ & $25.85 \pm 9.31$ & 0.351 \\
Gender: female $^{2}$ & $39(50)$ & $33(55)$ & 0.608 \\
Bipolar I $^{2}$ & $62(82)$ & $37(65)$ & $0.044^{*}$ \\
Any comorbid Axis I disorder $^{2}$ & $34(43)$ & $15(25)$ & $0.047^{*}$ \\
Substance abuse $^{2}$ & $25(32)$ & $12(19)$ & 0.124 \\
Anxiety disorder $^{2}$ & $12(15)$ & $5(8)$ & 0.297 \\
Eating disorder $^{2}$ & $7(9)$ & $4(6)$ & 0.755 \\
Rapid cycling in history $^{2}$ & $37(56)$ & $15(29)$ & $0.005^{*}$ \\
Suicide attempt in history $^{2}$ & $22(39)$ & $14(29)$ & 0.309 \\
Living situation (alone) $^{2}$ & $45(58)$ & $31(56)$ & 1.0 \\
Number of mood stabilizers $^{1}$ & $1.52 \pm 0.72$ & $1.26 \pm 0.49$ & $0.033^{*}$ \\
Use of antidepressants $^{2,3}$ & $27(45)$ & $17(37)$ & 0.433 \\
Use of antipsychotics $^{2,3}$ & $21(36)$ & $5(11)$ & $0.006^{*}$ \\
\hline
\end{tabular}

Figures in parentheses are percent values.

1 T test.

2 Fisher's exact test.

3 More than 6 months during follow-up.

Table 5. Rapid cycling during follow-up

\begin{tabular}{llll}
\hline & Rapid cycling & No rapid cycling & p value \\
\hline Age $^{1}$ & $41.79 \pm 11.35$ & $41.62 \pm 13.44$ & 0.943 \\
Age of onset $^{1}$ & $31.5 \pm 13.99$ & $26.18 \pm 10.19$ & 0.085 \\
Female $^{2}$ & $19(49)$ & $57(53)$ & 0.711 \\
Bipolar I $^{2}$ & $27(71)$ & $80(76)$ & 1.0 \\
Comorbid axis I disorder $^{2}$ & $12(31)$ & $39(38)$ & 0.558 \\
Substance abuse $^{2}$ & $11(28)$ & $27(25)$ & 1.0 \\
Anxiety disorder $^{2}$ & $7(18)$ & $11(10)$ & 1.0 \\
Eating disorder $^{2}$ & $1(3)$ & $9(8)$ & 0.291 \\
${\text { Early age of onset }(0-17)^{2}}_{\text {Rapid cycling in history }}{ }^{2}$ & $15(38)$ & $16(15)$ & 1.0 \\
Suicide attempt in history & $27(75)$ & $27(31)$ & $0.000^{*}$ \\
Living situation (alone) $^{2}$ & $17(59)$ & $19(23)$ & $0.001^{*}$ \\
Number of mood stabilizers $^{1}$ & $24(62)$ & $59(58)$ & 1.0 \\
Use of antidepressants $^{2,3}$ & $1.70 \pm 0.64$ & $1.26 \pm 0.59$ & $0.001^{*}$ \\
Use of antipsychotics $^{2,3}$ & $14(42)$ & $33(42)$ & 1.0 \\
& $10(31)$ & $17(22)$ & 1.0 \\
\hline
\end{tabular}

Figures in parentheses are percent values.

T test.

2 Fisher's exact test.

3 More than 6 months during follow-up.

typical antipsychotic than patients who remained stable ( $p<0.033$ and $\mathrm{p}<0.006$, respectively). There were no significant differences concerning gender, age, age of onset, living situation (alone vs. with family), suicide attempts in history and long-term antidepressant use during the follow-up period (table 4).

The Stanley Foundation Bipolar Network

\section{Rapid Cycling}

More than a quarter of the sample $(26.5 \%)$ had a rapidcycling course (i.e. at least 4 episodes within 12 months) during the follow-up period. Moreover, patients who actually suffered from rapid cycling significantly more often had a rapid-cycling course in their history $(\mathrm{p}<$ 
0.000) and were on more mood stabilizers than patients without rapid cycling $(\mathrm{p}<0.001)$. If patients had more than 4 episodes during the follow-up period, they significantly more often had at least one suicide attempt in history $(p<0.001)$. There were no significant differences between patients with or without a rapid-cycling course concerning age, age of onset, gender, comorbid disorders, alcohol or substance abuse, living situation (alone or with family) and long-term antidepressant or antipsychotic use during follow-up (table 5).

\section{Discussion}

In this article, the characteristics of the first 152 German patients enrolled in the SFBN as well as some features of the follow-up period are described. As far as the demographic and clinical variables are concerned, there are not many differences between our patient sample and other clinical samples of bipolar patients [9, 21, 22]. Gender, age, martial status, education and diagnosis are comparable with those of other studies. Like the American SFBN study participants [9], the majority of our patients was highly educated, but only one third was able to work in positions which met their qualifications. More than half of the sample worked below their qualifications, in sheltered workshops or were unable to work and therefore got an invalidity pension. This limitation of functioning was reported by the patients themselves and was also reflected by the low annual household income of less than 10,000 EUR for more than $30 \%$ of the study population. Thus, the German SFBN study population confirms the results of other naturalistic studies [9, 23].

The major discrepancy to other studies, however, is the difference in comorbid psychiatric disorders. While many studies describe a proportion of up to $50 \%$ of bipolar patients with an additional substance abuse [2, 24-26] and up to a $93 \%$ frequency of lifetime anxiety disorders in bipolar I patients [27], in our study, only $35.8 \%$ had an additional Axis I disorder. Like in other studies, alcohol abuse was the most frequent one (17.8\%) followed by anxiety disorders $(12.5 \%)$. The reason for such a low rate is not quite sure. A selection bias may be possible. With bipolar disorder often unrecognized, many patients may seek care in a setting specialized in their comorbid disorder. Additionally, most reports on high comorbidity rates are based on US populations which may not be comparable with conditions in Germany.

More than $40 \%$ of the patients report a rapid-cycling course in history, and almost $27 \%$ had 4 or more episodes during the 2.5 years of follow-up. While other studies describe different predictors for rapid cycling such as age, age of onset, female sex, bipolar II disorder or antidepressant use [28], our study could not confirm these results. There was only an association between rapid cycling and suicide attempts, rapid cycling in history and a higher number of mood stabilizers. These associations are not surprising. It is rather obvious that a single mood stabilizer is often not enough to prevent new episodes, the more severe the disorder is.

Concerning treatment, it has to be stated that despite our elaborated setting and state-of-the-art treatment, more than half of the patients experienced a relapse during follow-up. Patients with bipolar I disorder or a comorbid Axis I disorder were on highest risk for relapse. It is an obvious conclusion that we still lack a 'golden standard' in treatment, especially in this high-risk population of bipolar patients.

This study has a number of limitations to generalize these data. First of all, the study population was usually enrolled after hospitalisation in a university hospital. That is why this sample does not represent patients in the community but rather patients who are severely ill, which is also reflected by the high percentage of patients who had more than 20 episodes. Still, the major results of this study are comparable with other studies with clinical samples. Another limitation is that patients had to be willing to complete ratings and attend regular appointments. Usually, patients willing to do so were not hospitalised for their first episode, but had already been ill for several years. On the other hand, the SFBN has a number of strengths like standardized methodology, detailed prospective ratings of mood, sleep, life events and medication and continuous longitudinal follow-up.

Nonetheless, this study again reveals the high morbidity of this illness despite multiple treatment available and therefore emphazises the need for research in this particular field. 


\section{References}

1 Regier DA, Farmer ME, Rae DS, Locke BZ, Keith SJ, Judd LL, Goodwin FK: Comorbidity of mental disorders with alcohol and other drug abuse. Results from the Epidemic Catchment Area (ECA) Study. JAMA 1990;264:25112518.

2 Kessler RC, McGonagle KA, Zhao S, Nelson $\mathrm{CB}$, Hughes $\mathrm{M}$, Eschleman $\mathrm{S}$, Wittchen $\mathrm{H}$, Kendler KS: Lifetime and 12-month prevalence of DSM-III-R psychiatric disorders in the United States. Arch Gen Psychiatry 1994;51: 8-19.

3 Akiskal HS: The bipolar spectrum: New concepts in classification and diagnosis; in Grinspoon L (ed): Psychiatry Update: The American Psychiatric Association Annual Review. Washington, American Psychiatric Press, 1983.

4 Akiskal HS, Mallya G: Criteria for the 'soft' bipolar spectrum: Treatment implications. Psychopharmacol Bull 1987;23:68-73.

5 Akiskal HS, Pinto O: The evolving bipolar spectrum: Prototypes I, II, III, and IV. Psychiatr Clin North Am 1999;22:517-534.

6 Angst J: A brief history of bipolar disorder. J Bipolar Disord 1998;1:31-36.

7 Prien RF, Potter WZ: NIMH workshop report of treatment of bipolar disorder. Psychopharmacol Bull 1990;26:409-427.

8 Prien RF, Rush AJ: National Institute of Mental Health Workshop Report on the treatment of bipolar disorder. Biol Psychiatry 1996;40: 215-220.

9 Suppes T, Leverich GS, Keck PE Jr, Nolen WA, Denicoff KD, Altshuler LL, McElroy SL, Rush AJ, Kupka R, Frye MA, Bickel M, Post RM: The Stanley Foundation Bipolar Treatment Outcome Network. 2. Demographics and illness characteristics of the first 261 patients. $J$ Affect Disord 2001;67:45-59.
10 Leverich GS, Nolen WA, Rush AJ, McElroy SL, Keck PE Jr, Denicoff KD, Suppes T, Altshuler LL, Kupka R, Kramlinger KG, Post RM: The Stanley Foundation Bipolar Treatment Outcome Network. 1. Longitudinal methodology. J Affect Disord 2001;67:33-44.

11 Post RM, Nolen WA, Kupka RW, Denicoff KD, Leverich GS, Keck PE Jr, McElroy SL, Rush AJ, Suppes T, Altshuler LL, Frye MA, Grunze H, Walden J: The Stanley Foundation Bipolar Network. 1. Rationale and methods. $\mathrm{Br}$ J Psychiatry Suppl 2001;41:S169-S176.

12 Kupka RW, Nolen WA, Altshuler LL, Denicoff KD, Frye MA, Leverich GS, Keck PE Jr, McElroy SL, Rush AJ, Suppes T, Post RM: The Stanley Foundation Bipolar Network. 2. Preliminary summary of demographics, course of illness and response to novel treatments. $\mathrm{Br} \mathrm{J}$ Psychiatry Suppl 2001;41:S177-S183.

13 Leverich GS, Post RM: Life charting of affective disorders. CNS Spectrum 1998;3:21-37.

14 Wittchen HU, Wunderlich U, Gruschwitz S, Zaudig M: Strukturiertes und klinisches Interview für DSM-IV (SKID). Göttingen, Hogrefe 1997.

15 Hyler S: Personality Questionnaire with Two Additional Research Categories of Personality Disorders: The PDQ 4+. New York, State Psychiatric Institute, 1994.

16 Rush AJ Giles DE, Schlesser MA: The Inventory of Depressive Symptomatology (IDS): Preliminary findings. Psychiatry Res 1986;18:6587.

17 Young RC, Biggs JT, Ziegler VE: A rating scale for mania: Reliability, validity and sensitivity. Br J Psychiatry 1978;133:429-435.

18 Kay SR, Fiszbein A, Opler LA, et al: Positive and Negative Syndrome Scale (PANSS) for schizophrenia. Schizophr Bull 1987;13:261276.

19 Spearing MK, Post RM, Leverich GS, et al: Modification of the Clinical Global Impressions (CGI) Scale for use in bipolar disorder (BP): The CGI-BP. Psychiatry Res 1997;73: 159-171.
20 American Psychiatric Association: Diagnostic and Statistical Manual of Mental Disorders, ed 4. Washington, American Psychiatric Association, 1994.

21 Lish JD, Dime-Meenan S, Whybrow PC, Price RA, Hirschfeld RMA: The National Depressive and Manic-Depressive Association (DMDA) survey of bipolar members. J Affect Disord 1994;31:281-294.

22 Goodwin FK, Jamison KR: Manic-Depressive Illness. New York, Oxford University Press, 1990.

23 Coryell W, Sheftner W, Keller M, Endicott J, Klerman GL: The enduring psychosocial consequences of mania and depression. Am J Psychiatry 1993;150:720-727.

24 Brieger P: Comorbidity in bipolar affective disorder; in Marneros A, Angst J (eds): Bipolar Disorders: 100 Years after Manic-Depressive Insanity. Dordrecht, Kluwer Academic Publishers, 2000, pp 215-229.

25 Kessler RC, Rubinow DR, Holmes C, Abelson JM, Zhao S: The epidemiology of DSM-III-R bipolar I disorder in a general population survey. Psychol Med 1997;27:1079-1089.

26 McElroy SL, Altshuler LL, Suppes T, Keck PE Jr, Frye MA, Denicoff KD, Nolen WA, Kupka RW, Leverich GS, Rochussen JR, Rush AJ, Post RM: Axis I psychiatric comorbidity and its relationship to historical illness variables in 288 patients with bipolar disorder. Am J Psychiatry 2001;158:420-426.

27 Kessler RC: Comorbidity of unipolar and bipolar depression with other psychiatric disorders in a general population survey; in Tohen $M$ (ed): Comorbidity in Affective Disorders. New York, Dekker, 1999, pp 1-25.

28 Kilzieh N, Akiskal HS: Rapid cycling bipolar disorder: An overview of research and clinical experience. Psychiatr Clin North Am 1999;22: 585-607. 